\title{
ACUENDA, MONA, TEM ALIBÃ NA GIRA! A INFLUÊNCIA DO IORUBÁ NO LÉXICO GAY
}

Claudio Artur O. Rei (UNESA)

Cada um sabe a dor

E a delícia de ser o que é Não me olhe como se a polícia

Andasse atrás de mim

(Caetano Veloso ${ }^{1}$ )

Resumo: Este artigo é resultado de um trabalho feito ainda no mestrado, quando estudávamos Dialetologia do Português. Resultado de um sorteio, coube-nos falar sobre o dialeto gay. Para o levantamento do léxico abordado, recorremos a duas fontes: entrevistas a travestis que faziam trottoir na Praça Paris, no bairro da Glória, no Rio de Janeiro, e a dois terreiros de Candomblé, origem e base do iorubá no Brasil. Após a coleta e análise dos dados, percebemos que não havia domínio da língua ioruba, apenas de seu léxico disposto em estruturas sintático-morfológicas do português, até mesmo os aspectos semânticos estavam associados ao português. Baseados em Sumpf (1973) e Coseriu (1987), tentaremos observar algumas relações desse substrato utilizado na fala dos homossexuais.

Palavras-chave: dialeto gay, iorubá, Dialetologia.

Abstract: This article is the result of research already done in the master, when we studied Dialectology of the Portuguese. Result of a draw, fit us talk about the gay dialect. For the survey of the taken lexicon, we turn to two sources: interviews with she-males who were in trottoir, in Paris Square, in the neighborhood of Gloria, Rio de Janeiro, and two temples of Candomblé, Yoruba origin and base in Brazil. After collecting and analyzing the data, we realized that there was no domais of the Yoruba language, only its lexicon provisions of syntactic-morphological structures of the Portuguese, even the semantic aspects were associated with the Portuguese. Based in

1 “Dom de iludir". In VELOSO, Caetano (1993). Totalmente Demais. CD Philips n.o 830.145-2, f.11. 
Sumpf (1973) and Coseriu (1987), we shall try to watch some relations of this substrate used in the speech of homosexuals.

Key words: gay dialect, Yoruba, Dialectology.

Durante o curso de Mestrado, mais precisamente no ano 1999, cursamos a disciplina Dialetologia do Português. O professor trouxe vários temas à aula, e como não havia consenso na escolha, , houve a opção por sorteio. Coubenos, então, o léxico gay, o que, a princípio, pareceu-nos uma tarefa hercúlea em razão de não dominarmos o assunto nem sabermos onde pesquisar. Vencido o choque inicial, despimonos dos preconceitos sexuais e religiosos e fomos à busca de informações. Nosso primeiro contato foi com a internet, onde achamos a seguinte informação sobre o iorubá2:

Para aqueles que entram em contato com o iorubá pela primeira vez, talvez seja interessante saber que este idioma originário da África ocidental, de regiões que hoje fazem parte das repúblicas da Nigéria e do Benin, é uma língua milenar, com relatos de muitos séculos de história antes da chegada dos europeus à capital de seu reino, Ilé-Ifé. Ao lado do haússa, o iorubá é uma das mais importantes línguas da Nigéria, sendo falado por aproximadamente 25 milhões de pessoas naquele país e por milhões de descendentes de escravos africanos em países onde houve algum espaço para

2 ioruba adj. s.2g.; iorubá adj. s.2g. http://www.academia.org.br/abl/cgi/cgilua.exe/sys/start. htm?sid=23 
a cultura iorubá sobreviver, como no Brasil, na forma conhecida como nagô, e em Cuba. (Pierre Fatumbi Verger) ${ }^{3}$.

No Brasil, o idioma iorubá se manteve presente pela tradição nas rezas, cantigas, e saudações usadas no Candomblé, religião de origem africana trazida pelos negros escravos. Mas a pergunta então nos chega à mente: onde esse dialeto se enquadra no léxico gay? Há dois aspectos que se podem abordar para nortear tal associação, um deles é a necessidade existente, via de regra, no ser humano de se apegar a uma religião; outro seria o preconceito existente nas religiões tidas como tradicionais contra os homossexuais que se assumem publicamente.

Por ser o Candomblé uma religião nascida de uma segregação sociorracial e associada, durante muito tempo, à feitiçaria e à magia negra, houve uma total repulsa a essa crença, e a religião, então, por se ver marginalizada, passou a não fazer as mesmas distinções e restrições que a sociedade Ihe fazia. Nesse sentido, pode-se dizer que foi a "abertura de portas" para o ingresso dos homossexuais poderem dedicar-se a uma crença religiosa, sem que fossem discriminados ou tivessem de abdicar de sua orientação sexual em prol de um dogma religioso.

3 http://ogumxoroke.tumblr.com/post/61044303860/gramatica-yoruba 
Entretanto, não se pode afirmar que, nesse mundo da espiritualidade, não exista a discriminação, pois ela existe. Há duas grandes facções do culto aos orixás no Brasil: a Umbanda e o Candomblé. A primeira está mais ligada ao sincretismo religioso, na qual a presença de santos católicos se funde a orixás africanos, como se fosse um "catolicismo espiritualizado", contendo não só as concepções do culto africano como os dogmas da Igreja Católica. Na Umbanda, canta-se, reza-se e salva-se em português. Já o Candomblé mantém as raízes africanas, não há o sincretismo, e os principais rituais são ainda cantados em iorubá. Talvez seja esse afastamento do conceito de pecado, mantido pela Umbanda, que faz com que os homossexuais optem pelo Candomblé, visto que socialmente ocorre este tipo de acusação: terreiros de Candomblé são frequentados por homossexuais.

À luz desse raciocínio, vai-se esclarecendo o uso do dialeto iorubá na fala dos homossexuais. Por não dominarem por completo essa fala nem suas estruturas morfossintáticas, os falantes desse dialeto acabam por aplicar no iorubá as estruturas do português em todos os níveis. A esse respeito, aponta-nos Sumpf (1963: 14-15):

Reencontramos a propósito do morfema os procedimentos de definição com que já deparamos a propósito de fonema, mas no plano sintáctico: unidade nominal etc. 
Este problema tem a sua importância, pois durante muito tempo foi o vocábulo a unidade nominal e, por esse motivo, nos achávamos necessariamente arrastados para um todo complexo: significantefuncional, se vão para a ideia aristotélica de substância.

As dificuldades, aqui, são bem conhecidas:

Em que língua ou em que nível da língua se há-de efectuar a análise morfemática? [...]

Como separar? Segundo a intuição do locutor nativo segundo o sentido?

Geralmente, o problema não se põe em termos tão empíricos. O problema é: em que bases teóricas separar?

A segmentação pode fazer-se na continuidade com a segmentação fonológica: importância dos marcos, das pausas, do agrupamento distribucional. É evidente que o problema é o de segmento demasiado (over-cut) ou o de não segmentar bastante (under-cut). Em definitivo, a segmentação depende da ideia teórica que fazermos da gramática (análise em constituintes imediatos, gramática gerativa etc.).

Assim, como no próprio título Acuenda, mona, tem alibã na gira!, veem-se as palavras acuenda, mona, aliba $\tilde{a}^{4}$

4 Devido à tradição oral do iorubá, muitas palavras passam por variações fonéticas, como essa em questão, que pode ser ouvida como aribã e anibã, além da forma alibã, significando a mesma coisa. Tal processo é bastante frequente, e a escolha de qualquer variante fonética aqui feita é mera casualidade, da mesma forma em que a grafia das palavras selecionadas não segue o padrão ortográfico dos dicionários de iorubá, optou-se simplesmente pela transcrição aproximada da pronúncia das palavras. 
e gira empregadas numa estrutura frasal completamente portuguesa, com o uso da forma verbal tem, no registro coloquial, pois o verbo em questão está sendo empregado com sentido de existir e a contração na. A expressão acima citada pode ser mais bem compreendida dentro desse aspecto, se traduzida: "se manda, bicha, tem polícia na área". Nota-se, então, que não se trata de um dialeto exclusivamente iorubá, mas sim o emprego do léxico iorubá numa formação portuguesa. A forma verbal em questão, acuenda, está flexionada de acordo com o paradigma da primeira conjugação, como todos os outros verbos formados a partir de palavras oriundas desse dialeto. Tem-se como alguns exemplos azuelar (falar, dizer, pronunciar, e, em alguns contextos, paquerar), maiongar (banhar-se, proveniente de maionga, banho), enquizilar (contrariar, aborrecer, implicar. $\mathrm{O}$ verbo é formado por parassíntese, pois deriva do substantivo quizila, que traz, em si, toda uma ideia de contrariedade), cufar (matar), copar (cortar) olegarar (roubar, ou a expressão muita usada no meio: "dar a Elza"), adochar (influenciar alguém, "fazer a cabeça da pessoa". Um caso de sufixação, pois adocho é um preparado que é posto na cabeça de um iniciado no Candomblé no dia se sua apresentação pública). Excetuando-se os casos em que se percebe o processo derivacional, não se pode dizer se, etimologicamente, essas 
palavras eram verbos em iorubá: acuendar, azuelar, cufar, copar, olegarar, por exemplo.

A esse respeito nos atesta Sumpf (1973: 15):

Como se viu, as dificuldades prendemse com a diversidade das línguas, com o facto de que a linguagem se não mesmo com a comunicação. Reencontramos aí as dificuldades de qualquer ciência - a que se prende com a oposição entre abstrato e concreto, mas reencontramos também uma dificuldade que está na base de toda a ciência dita humana - a que se prende entre parcial e global.

Curioso, também, é o fato de não ser esse o único processo de formação de verbos. Muitas vezes, a ideia verbal é formada com o auxílio de um verbo em português mais a palavra em iorubá, como nestes exemplos: tirar o achó (despir-se), fazer o ajeun (almoçar ou jantar), fazer o baco (manter relações sexuais), dar ou fazer ossé (banhar-se, limpar-se), ou mesmo usar os verbos de uso comum na língua como ter, fazer, tirar em sintagmas onde estejam misturados elementos do português e do iorubá: tirar o abatá (tirar o sapato), fazer lorogun ou ejó (fazer fofoca), ter indaca de afofô (ter língua de matraca, pessoa faladeira).

Um processo raro na formação de verbos é o sintagma substantivo + adjetivo com valor verbal: A mona achó odara 
(veste-se bem) ou A mona achó matin (veste-se mal), ou omintoró ("água de banheiro", urinar).

Entretanto, não é só em relação a verbos que se percebe a mescla das duas línguas. Vários processos são usados na formação de adjetivos e substantivos, nos quais se tem a palavra iorubá como base mais algum elemento mórfico português, criando-se assim um neologismo dialetal híbrido ${ }^{5}$, como nos casos de gongado (pessoa que foi escarnecida por outrem), pembado (pessoa que está sob o efeito de feitiço), bolado (pessoa confusa). Sobre o termo bolado pode-se dizer que já se tornou do domínio público, sendo utilizado por pessoas de diferentes grupos sociais, como ocorreu também com o termo caô, que, originalmente, era uma invocação ao orixá Xangô, e hoje tem outra acepção semântica, como na expressão "estar de câo" (estar inventando, mentindo). Sobre essa socialização de um termo, fala-nos Guilbert (1975: 38):

Se a palavra é uma unidade desprovida de realidade linguística fora do contexto sintático da frase, ela é também a representação de um núcleo de significação para o locutor e toda a

5 Sobre isso, assinala Alves (1990: 14) Ao contrário dos neologismos fonológicos, os neologismos sintáticos supõem a combinatória de elementos já existentes no sistema linguístico português. Classificam-se em derivados, compostos, compostos sintagmáticos e compostos formados por siglas ou acronímicos, são denominados sintáticos porque a combinação de seus membros constituintes não está circunscrita exclusivamente ao âmbito lexical (junção de um afixo a uma base), mas concerne também ao nível frástico: o acréscimo de prefixos ou de sufixos pode alterar a classe gramatical da palavra-base, a composição tem caráter coordenativo e subordinativo; os integrantes da composição sintagmática e acronímica constituem componentes frásticos com o valor de uma unidade lexical. 
comunidade falante como parte de uma rede semântica que define a experiência, a cultura de uma sociedade; é, portanto, necessário considerar o léxico como a coleção dessas unidades. Da mesma forma, são definidos os "signos" e as "palavras" que só têm existência na memória de cada indivíduo falante e na da massa falante pela referência às escolhas e aos conceitos que eles designam. Mas como alcançar a descrição léxica de uma comunidade linguística? Ela pode ser considerada como representante de certa homogeneidade, do ponto de vista das regras de produção de frases; ela é surpreendentemente diversa pelo vocabulário dos locutores que a constituem.

Nota-se, também, que, em muitos casos, o processo da reduplicação ou redobro é usado com valor de ênfase valorativa ou pejorativa. A palavra matin significa ruim, pouco, feio dependendo do contexto, assim, numa oração do tipo "O acué tá matin-matin" (O dinheiro está pouco), percebese, claramente que o redobro tem valor enfático mostrando que a situação financeira está uó (uó é o termo que designa tudo de ruim, mau gosto, desagradável, antipático, chato e palavras que se enquadrem nesse campo semântico. Também já é um termo de conhecimento e domínio públicos). Outro exemplo é o oju crê-crê (olho grande ou olho gordo, mas no sentido conotativo da expressão). 
Se, por um lado, o redobro é um processo frequente, a redução vocabular também o é. Mucunã que significa cabelo, constantemente é reduzido a muco, dundun que significa negro, preto, também é reduzido a simplesmente dunda.

Os termos utilizados no dialeto gay $^{6}$ são de naturezas bastante distintas, como se está podendo perceber, além dos termos da conversação diária, há, também, os termos mais específicos, isto é, aqueles que se referem às pessoas. Assim, tem-se: homem é ocó, mulher é mona (os homossexuais se tratam por esse termo, aludindo ao papel feminino exercido por eles ${ }^{7}$ ), pederasta é adé (adé firó é passivo e adé fontó é ativo), lésbica é monocó (mona + ocó, com apócope do a), prostituta é mona de oló (mulher de rua); travesti é mona de ekê (mulher de fingimento, mentira); rapaz muito novo é erê (inclusive é o nome de uma entidade infantil do Candomblé); velho é adariboce, cacu ou cacarucaio(a); pessoas pouco inteligentes são chamadas de ajé ou coce. Algumas outras denominações advêm da junção de outras palavras, como por exemplo: itaba é cigarro, itaba deungira (ou mungira) é maconha, e a expressão o ocó é da itaba deungira se refere a um traficante do sexo masculino, e ocó mavambo é

6 Tal expressão foi observada na fala tanto na entrevista com os travestis quanto nos terreiros de Candomblé, o que nos levou a crer que seja do domínio dos homossexuais a expressão "dialeto gay", para designar o uso que eles fazem do ioruba em suas interações.

7 Quando perguntei aos travestis, por que razão eles se tratavam de mona, já que tal termo significa mulher, a resposta dada foi essa. 
marginal. Observamos que não há referência a marginais do sexo feminino, possivelmente, usarão a desinência $\{-a\}$, na palavra mavambo (mona *mavamba).

As partes do corpo humano também são enfatizadas no dialeto gay. Cabeça é ori; olhos são oju; vagina é amapô, mapoa, mapô, poá; pênis é ocani; nádegas é edi, idi; fezes é nena, daí uma expressão largamente usada no dialeto gay: Ter ou Estar com nena no ori.

Às vezes, ocorre a necessidade de se construir uma estrutura por meio de recursos metafóricos, metonímicos ou mesmo perifrásticos, para definir o que se quer dizer, como em ilê de baco (ilê é casa e baco é o ato sexual) que traduz a ideia de motel; dofona, que é o título que a pessoa recebe quando é a primeira da fila numa iniciação no Candomblé, também pode referir-se à AIDS, numa alusão explícita ao medo maior, ao primeiro medo, àquilo que vem inicialmente à cabeça; bajé que significa menstruação e é usado, principalmente, por travestis para designar a impossibilidade de praticar sexo devido à diarreia; consultar o ifá pode ter duas significações: recorrer ao jogo, já que Ifá significa adivinhação, também é o nome de um jogo, ou, numa acepção mais metafórica, representa procurar informar-se sobre algo ou alguém, sem que seja necessariamente por meio de alguma arte divinatória, e eró quer dizer segredo. 
Dessa forma, percebe-se que o dialeto gay é marcado pela presença do iorubá, só que há ressalvas a serem feitas em relação a isso. Nota-se que a presença de palavras soltas em enunciados com estrutura morfossintática portuguesa não demonstra domínio da língua iorubá, pois dominar vocabulário não é dominar uma língua, o que ocorre nesses casos é apenas um processo de transculturação idiomática, analogamente ao que se dá na área tecnológica com alguns anglicismos, ou na área gastronômica com alguns galicismos e italianismos. O ioruba, na língua portuguesa, é um substrato mantido, oralmente, pelas tradições religiosas do Candomblé, daí se inferir que muito se perdeu e se transformou nesses quatro séculos. Por essa razão, têm-se construções do tipo: A mona de ekê estava com o obé-shirê na mocó (O travesti estava coma navalha na bolsa) ou O adé está fazendo lorogun com meu oruncó (A bicha está fazendo fofoca com o meu nome). Percebe-se claramente que só há o domínio do vocabulário, entretanto, não há o domínio da estrutura linguística do iorubá.

Ocorre, ainda, um decalque ${ }^{8}$ semântico, isto é, a mesma conotação existente em palavras da Língua Portuguesa sofre uma simples tradução no iorubá, sem que se corrobore a equivalência semântica desse termo com o dialeto, como na palavra adié que

8 Para mais informações acerca do termo decalque, ver Alves, 1990: 79. 
significa, primeiramente, galinha e é também usada com a ideia figurada de homem ou mulher de comportamento promíscuo. Da mesma forma, há muito se perdeu o paradigma de desinências das conjugações verbais, por isso se empregam as desinências regulares dos verbos de primeira conjugação do português, por serem considerados de maior produtividade.

Reitera-se, então, que o uso do iorubá no dialeto gayé uma forma de se criar uma linguagem na qual apenas as pessoas que estejam inseridas nessa realidade possam compreender. Mais uma vez, apoiamo-nos em Guilbert (1975: 38):

Os locutores estão envolvidos em subgrupos sociais e profissionais que possuem um estoque de palavras particulares que somente eles conhecem, usam. Uma grande diversidade existe entre os indivíduos do mesmo nível social, conforme a capacidade de memorização segundo a idade, o grau de cultura. Existem, além disso, as palavras de valor sinonímico cujo emprego se distribui segundo a classe social dos locutores e as situações de comunicação. ${ }^{9}$

Mais uma vez, nota-se que há um fechamento em torno dos homossexuais, sendo que, nesse momento, imposto por eles próprios, ao criarem um tipo de comunicação mais restrita. A esse respeito, fala-nos Coseriu (1987: 31):

9 Julgamos oportuna essa citação, pois não importa o grau de escolaridade ou o nível social, os homossexuais, de forma geral, dominam essa linguagem. 
O tema de nossa comunicação diz respeito a uma relação entre dois termos: o da linguagem e o da compreensão do homem atual. Pois bem, uma relação pode ser uma relação entre termos equivalentes e que se determinam reciprocamente ou uma relação entre um termo determinante e um determinado. No primeiro caso, deveríamos supor para os termos de nosso tema que a linguagem atua sobre o entendimento do homem, que contribui para esse entendimento, mas que, por sua vez, o entendimento do homem se reflete na linguagem e contribui para modifica-la. No segundo caso, o termo determinante poderia ser o primeiro ou o segundo. [...] Por conseguinte, numa nova formulação, nosso tema seria: "Em que medida pode contribuir o fenômeno da linguagem, ou melhor ainda, o correto entendimento da linguagem, para a compreensão do homem atual?"

Deixamos claro que se trata de uma pesquisa inicial, portanto carece de maior aprofundamento. Mas supomos que já oferece uma contribuição razoável para quem se interessa por temas linguísticos, sobretudo por linguagens especiais; por isso, temos ciência de que nosso artigo está bastante enxuto em relação ao uso do iorubá no léxico gay, mas ressaltamos que o material recolhido foi fruto de entrevistas a travestis que faziam trottoir na Praça Paris, no bairro da Glória, no Rio de Janeiro, e de visitas a dois terreiros de Candomblé. Gostaríamos de ressaltar, 
hic et nunc, que a recepção à nossa pesquisa foi muito bem recebida, tanto pelos travestis quanto pelos candomblecistas, que não se opuseram, de forma alguma, a nos dar informações e explicações acerca do uso do iorubá, salvo apenas os adeptos do Candomblé. Uma limitação ética que excluiu palavras que estivessem ligadas aos atos ritualísticos ou preceituais, expressão que eles mesmos usaram.

\section{REFERÊNCIAS}

ALVES, leda Maria (1990). Neologismo: criação lexical. São Paulo: Ática. (Série Princípios, n.191).

COSERIU, Eugênio (1987). O Homem e sua Linguagem. 2ed. Rio de Janeiro: Presença (Coleção Linguagem, n.16).

GUILBERT, Louis (1975). La Créativité Lexicale. Paris: Larousse.

SUMPF, Jean. "Filosofia da linguagem - como e porquê." In SUMPF, Jean; GRANGER, Gilles-Gaston.; BOUVERESSE, Jacques \& GAUVIN, J. (1973). Filosofia da Linguagem. Coimbra: Almedina.

Claudio Artur O. Rei é Doutor e Mestre em Língua Portuguesa pela UERJ, instituição na qual também cursou a graduação e a especialização. Professor Adjunto da Universidade Estácio de Sá, desde 2000, onde acumula o cargo de coordenador do curso de Letras, do campus Nova Iguaçu. Desenvolve pesquisa na área de Estilística, com subsídios em Semântica e Semiótica, voltada para uma modalidade funcional em que se discutem as escolhas lexicais a partir das variantes eleitas a serem aplicadas. Professor do Ensino Médio desde 1990 e professor do Ensino Fundamental desde 1994, na rede pública e privada. Contato: arturrei@uol.com.br 